\title{
Radiofrequency Sacral Rhizotomy for the Management of Intolerable Neurogenic Bladder in Spinal Cord Injured Patients
}

\author{
Kang Hee Cho, M.D., Sang Sook Lee, M.D.
}

Department of Rehabilitation Medicine, Chungnam National University School of Medicine, Daejeon 301-172, Korea

Objective To investigate the effect of radiofrequency (RF) sacral rhizotomy of the intolerable neurogenic bladder in spinal cord injured patients.

Method Percutaneous RF sacral rhizotomy was performed on 12 spinal cord injured patients who had neurogenic bladder manifested with urinary incontinence resisted to an oral and intravesical anticholinergic instillation treatment. Various combinations of S2, S3, and S4 RF rhizotomies were performed. The urodynamic study (UDS) was performed 1 week before RF rhizotomy. The voiding cystourethrogram (VCUG) and voiding diaries were compared 1 week before and 4 weeks after therapy. Total volume of daily urinary incontinence ( $\mathrm{ml} /$ day) and clean intermittent catheterization ( $\mathrm{ml} /$ time) volume of each time were also monitored.

Results After RF sacral rhizotomy, bladder capacity increased in 9 patients and the amount of daily urinary incontinence decreased in 11 patients. The mean maximal bladder capacity increased from 292.5 to $383.3 \mathrm{ml}$ $(\mathrm{p}<0.05)$ and mean daily incontinent volume decreased from 255 to $65 \mathrm{ml}(\mathrm{p}<0.05)$. Bladder trabeculation and vesicoureteral reflux findings did not change 4 weeks after therapy.

Conclusion This study revealed that RF sacral rhizotomy was an effective method for neurogenic bladder with uncontrolled incontinence using conventional therapy among spinal cord injured patients.

Key Words Spinal cord injury, Neurogenic bladder, Hyperactive detrusor muscle, Radiofrequency, Sacral rhizotomy

Received August 30, 2011; Accepted January 16, 2012

Corresponding author: Sang Sook Lee

Department of Rehabilitation Medicine, Chungnam National University Hospital, 282, Munhwa-ro, Jung-gu, Daejeon 301-172, Korea

Tel: +82-42-280-7811, Fax: +82-42-256-6056, E-mail: drlovingss@naver. com

(c) This is an open-access article distributed under the terms of the Creative Commons Attribution Non-Commercial License (http:// creativecommons.org/licenses/by-nc/3.0) which permits unrestricted noncommercial use, distribution, and reproduction in any medium, provided the original work is properly cited.

Copyright () 2012 by Korean Academy of Rehabilitation Medicine

\section{INTRODUCTION}

The neurogenic bladder of spinal cord injured patients is classified in several clinical aspects according to the injury level and severity. Patients with neurogenic detrusor overactivity have compromised bladder storage volume and increased urinary incontinence due to elevated intravesical pressure.

To suppress the pressure of the detrusor muscle and to reduce the volume of urinary incontinence, anticholinergic agents are frequently used as the treatment of choice 
for neurogenic detrusor overactivity in spinal cord injury (SCI). At the same time, it also has side effects, such as dry mouth, constipation, nausea, and visual field defects. Moreover, some patients have a refractory response to the maximal dosage of oral medication. ${ }^{1}$ To avoid the systemic side effects of medication, intravesical anticholinergic instillation and botulinum toxin injection to the detrusor muscle are performed, but these therapies risk infection and need to be performed repeatedly because their effects are not permanent. ${ }^{2-4}$

Surgical treatments for the intolerable neurogenic bladder aim to reduce the pressure of the detrusor muscle and to prevent complications of the upper urinary tract. For this reason, augmentation cystoplasty, which directly expands the bladder volume using intestinal segments, has become a standard surgical option. An alternative to surgery is functional reconstruction of the hyperreflexic bladder using selective sacral rhizotomies. Selective sacral rhizotomy has benefits in improving the urinary incontinence and eliminating detrusor overactivity. ${ }^{5}$ Moreover, there are fewer complications compared to augmentation cystoplasty and intermittent catheterization can be applied even if an areflexic bladder occurs. However, this procedure has certain drawbacks as well, such as a weakening of the urethral sphincter and pelvic floor muscles, abolition of the reflex erection, and reflex ejaculation among males. In addition, because this intervention is irreversible, it prevents spinal cord regeneration. ${ }^{6}$

Percutaneous radiofrequency (RF) sacral rhizotomy is considered a valid alternative with compensating surgical options. RF ablate the nerve by generating heat around the nervous tissue using high frequency waves, resulting in a denaturation of protein in nerve fibers. It is used to treat neuropathic pain, sympathetically maintained pain, and chronic spinal pain.

As a non-surgical method, RF sacral rhizotomy is used in managing trigeminal neuralgia stellate ganglion block, spinal nerve block, and percutaneous dorsal rhizotomies. It also has the benefits of simplicity, safety, short hospital stay, and few complications. ${ }^{7}$

There have been reports of RF sacral rhizotomy reducing the pressure of the detrusor muscle and increasing the bladder volume; ${ }^{8,9}$ however, a specific and quantified research on the bladder maximum volume and variety of conformation has not been reported. The aim of this study is to determine the significant and clinical effects of percutaneous RF sacral rhizotomy as a treatment of neurogenic bladder in SCI by observing the improvement of urinary incontinence and bladder volume through comparing before and after the procedure.

\section{MATERIALS AND METHODS}

\section{Subjects}

From March 2006 to July 2011, twelve spinal cord injured patients ( 11 males and 1 female, mean age of $49.7 \pm 11.9$ ) was presented at Chungnam National University Hospital for the treatment of neurogenic bladder. The patients suffered from frequent urination and urinary incontinence though anticholinergic medicine was administered over 6 months. The subjects took a maximal dosage of multiple oral medications at acceptable levels to avoid side effects. According to the UDS, the maximum cystometric capacity of the subjects was under $300 \mathrm{ml}$ and compliance was under $15 \mathrm{ml} / \mathrm{cmH} 2 \mathrm{O}$. Of the $12 \mathrm{pa}-$ tients, 11 patients were diagnosed with neurogenic detrusor overactivity and one patient was diagnosed with detrusor areflexia. The mean interval between occurrence of injury and UDS was $54.1 \pm 43.7$ months. Four patients were injured at the cervical level, seven patients at the thoracic level, and one patient was injured at the lumbar

Table 1. Characteristics of the Patients with Spinal Cord Injury

\begin{tabular}{|c|c|c|c|c|}
\hline Patient & $\begin{array}{l}\text { Age/ } \\
\text { Sex }\end{array}$ & $\begin{array}{l}\text { Level (ASIA } \\
\text { impairment } \\
\text { scale) }\end{array}$ & $\begin{array}{c}\text { Time since } \\
\text { injury } \\
\text { (months) }\end{array}$ & $\begin{array}{l}\text { Voiding } \\
\text { method }\end{array}$ \\
\hline 1 & $34 / \mathrm{F}$ & $\mathrm{C} 4(\mathrm{~B})$ & 60 & $\mathrm{CIC}$ \\
\hline 2 & $46 / \mathrm{M}$ & C6 (D) & 12 & Self voiding \\
\hline 3 & $52 / \mathrm{M}$ & $\mathrm{T} 10$ (A) & 7 & $\mathrm{CIC}$ \\
\hline 4 & $53 / \mathrm{M}$ & T5 (A) & 88 & $\mathrm{CIC}$ \\
\hline 5 & $28 / \mathrm{M}$ & $\mathrm{T} 4$ (A) & 28 & $\mathrm{CIC}$ \\
\hline 6 & $69 / \mathrm{M}$ & $\mathrm{L} 1$ (A) & 39 & Diaper voiding \\
\hline 7 & $60 / \mathrm{M}$ & C4 (A) & 76 & $\mathrm{CIC}$ \\
\hline 8 & $49 / \mathrm{M}$ & $\mathrm{T} 10$ (A) & 16 & CIC \\
\hline 9 & $37 / \mathrm{M}$ & $\mathrm{T} 4$ (B) & 120 & Self voiding \\
\hline 10 & $51 / \mathrm{M}$ & T8 (A) & 34 & $\mathrm{CIC}$ \\
\hline 11 & $62 / \mathrm{M}$ & T3 (A) & 142 & $\mathrm{CIC}$ \\
\hline 12 & $55 / \mathrm{M}$ & C4 (A) & 32 & $\mathrm{CIC}$ \\
\hline
\end{tabular}

ASIA: American spinal injury association, CIC: Clean intermittent catheterization 
level. A complete injury was observed in 9 patients and incomplete injury in 3 patients (Table 1). Nine patients urinated by performing intermittent catheterization (IC) and 3 patients urinated by self-voiding control. Exclusion criteria included patients who had urinary tract disease before SCI or had their urinary tract operated. The subjects did not change their bladder medication during their study participation.

\section{Methods}

All subject underwent voiding cystourethrogram (VCUG) and UDS 1 week before a percutaneous RF sacral rhizotomy was performed. Four weeks after the procedure, a repeat VCUG was done. From 1 week before to 4 weeks after the procedure, a voiding diary was collected from each enrolled patient. It included a recording of the total amount of daily water intake and output, daily average CIC volume, residual urine, intervals of urination, and daily urinary incontinence volume. Incontinence volume was recorded by measuring the weight of diapers.

Duet ${ }^{\circledR}$ LOGIC G2 (Mediwatch Plc, FL, USA) was used for the UDS measuring the maximum cystometric capacity, compliance, and detrusor pressure at the maximum cystometric capacity during the storage phase. The bladder was filled with $60 \mathrm{ml} / \mathrm{min}$ of warm saline $\left(20-30^{\circ} \mathrm{C}\right)$. Maximum cystometric capacity was determined as the total amount of filling saline when leakage occurred. Detrusor pressure at the maximum cystometric capacity was determined by the difference between maximal intravesical pressure and abdominal pressure. Measuring the pressure in the bladder using double lumen catheter and abdominal pressure was recorded through a rectal probe. Compliance is determined by a change in volume divided by a change in baseline pressure with filling.

To evaluate the bladder function by VCUG, the bladder was filled with $36^{\circ} \mathrm{C}$ of normal saline with contrast. Maximal bladder volume and bladder trabeculation were evaluated at a filling phase in the period before micturition. Maximal bladder volume was determined when leakage occurred or the catheter was forced out. Vesicoureteral reflux was evaluated at a voiding phase inducing micturition with suprapubic tapping or compression.

The RF was performed at bilateral S2 or S3 roots. If there was difficulty with approaching S2 or S3 foramen, the S4 root was considered. Subjects were fully informed of the risks and side effects that they might experience during this procedure. In a prone position, a 22 gauge needle and stylet was inserted on the skin surface to the sacral roots of the S2, S3, and S4 levels under fluoroscopic guidance (Fig. 1). Next, the stylet was removed from the needle and an electrode connecting NT1000 was inserted (Neurotherm Inc, MA, US). The bilateral sacral root was initially identified through a stimulating pulse of $2 \mathrm{~Hz}$, $0.2 \mathrm{~V}$. The voltage progressively increased by $0.8 \mathrm{~V}$ until contraction of the multifidus close to the sacrum could be seen and contraction of the lower extremity muscles could not be seen. Impedance was 300-1,000 $\Omega$. The thermolesion was performed $90-120$ seconds at $90^{\circ} \mathrm{C}$.

Maximum cystometric capacity, compliance, and detrusor pressure of the maximum cystometric capacity during UDS were measured before RF sacral rhizotomy began. Maximal bladder capacity, vesicoureteral reflux,
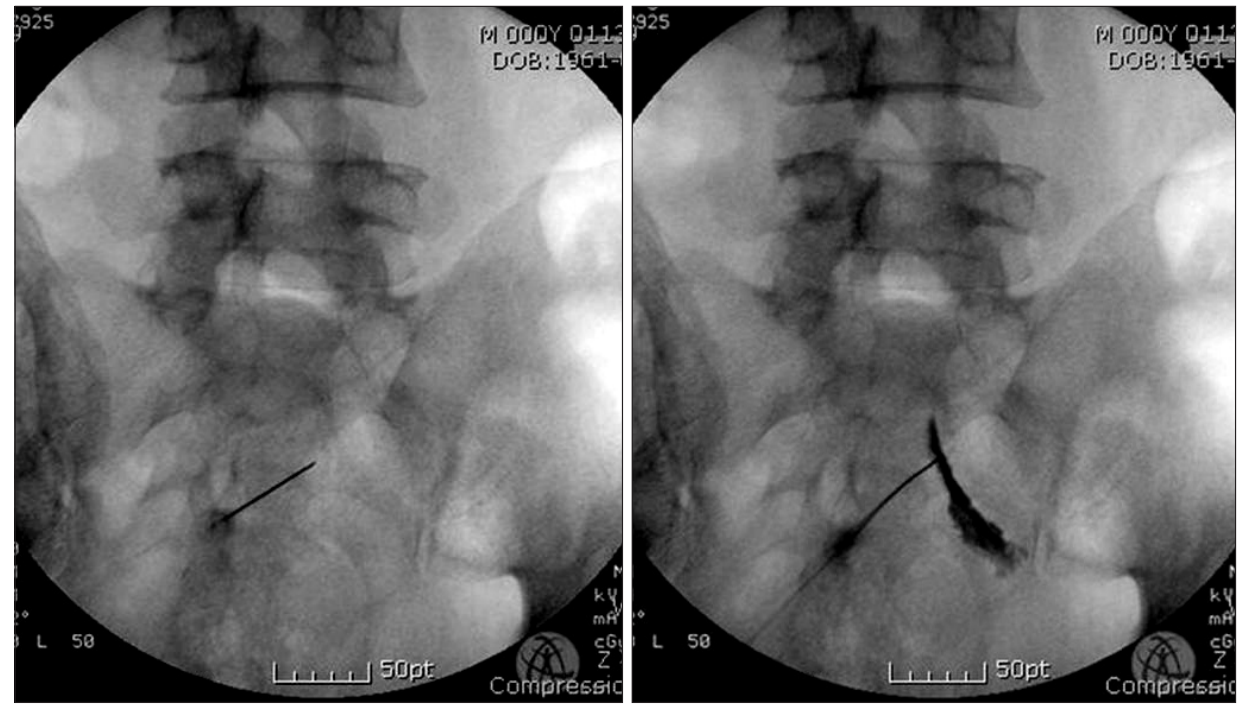

Fig. 1. Selective nerve root infiltration of S2 root. Left anteroposterior roenterogram shows the proper placement of the spinal needles at S2 sacral foramen for radiofrequency sacral rhizotomy. Right side shows the outline of $\mathrm{S} 2$ nerve root by the contrast material. 
and bladder trabeculation by VCUG were compared before and after procedure. Bladder trabeculation was classified by 4 groups based on severity and morphology (Grade 0: none bladder trabeculation, Grade 1: slight to moderate, Grade 2: severe, and Grade 3: severe with formation of diverticula). ${ }^{10}$ The average CIC volume and total amount of daily incontinence using a self-reported voiding diary were compared before and after treatment.

Wilcoxon Signed Ranks test was used to compare bladder capacity before and after percutaneous RF sacral rhizotomy, and Spearman correlation was performed to evaluate the association between period of time since injury and efficacy of rhizotomy. Statistical analysis was carried out with SPSS version 12.0. A p <0.05 level was considered significant.

Table 2. Comparison of Clinical Parameters before and after Radiofrequency Sacral Dorsal Rhizotomy

\begin{tabular}{llc}
\hline \multicolumn{1}{c}{ Parameter } & Before & After \\
\hline Average CIC volume of each time (ml) & $304 \pm 109$ & $467 \pm 134^{*}$ \\
Total amount of incontinence $(\mathrm{ml})$ & $255 \pm 68$ & $65 \pm 91^{*}$ \\
\hline Values are mean \pm standard deviation & & \\
CIC: Clean intermittent catheterization & \\
${ }^{*} \mathrm{p}<0.05$ &
\end{tabular}

\section{RESULTS}

Voiding diary: comparison of the average CIC volume and total amount of daily incontinence before and after percutaneous RF sacral rhizotomy

The average clean intermittent catheterization volume increased from $303.7 \pm 109.1 \mathrm{ml}$ to $467.2 \pm 134.4 \mathrm{ml}(\mathrm{p}<0.05)$ and total amount of daily incontinence decreased from $254.9 \pm 68.1 \mathrm{ml}$ to $65.2 \pm 91.3 \mathrm{ml}(\mathrm{p}<0.05)$. Intervals of urination increased in all cases and urinary incontinence improved in 11 cases (Table 2).

VCUG: comparison of the maximal bladder capacity, vesicoureteral reflux, and bladder trabeculation before and after percutaneous RF sacral rhizotomy

Among the 12 patients, 10 increased maximal bladder capacity. Maximum bladder capacity increased from $295.5 \pm 137.1 \mathrm{ml}$ to $383.3 \pm 190.4 \mathrm{ml}(\mathrm{p}<0.05)$. There were no significant differences regarding the duration of SCI or neurologic level of injury.

In 1 patient, who was observed bilateral VUR (Grade I), VUR grade did not change. Based on bladder trabeculaion grade, two patients were in Grade 0, six were in Grade 1, and four were in Grade 3. There were no significant changes of bladder trabeculation grade after the procedure (Table 3).

Table 3. Comparison of Voiding Cystourethrographic Findings before and after Radiofrequency Sacral Dorsal Rhizotomy

\begin{tabular}{|c|c|c|c|c|}
\hline \multirow[b]{2}{*}{ Patient } & \multicolumn{2}{|c|}{ Before } & \multicolumn{2}{|c|}{ After } \\
\hline & $\begin{array}{c}\text { Maximal bladder } \\
\text { capacity (ml) }\end{array}$ & $\begin{array}{c}\text { Trabeculation } \\
\text { (Grade) }\end{array}$ & $\begin{array}{c}\text { Maximal bladder } \\
\text { capacity }(\mathrm{ml})\end{array}$ & $\begin{array}{c}\text { Trabeculation } \\
\text { (Grade) }\end{array}$ \\
\hline 1 & 100 & 0 & 270 & 0 \\
\hline 2 & 300 & 1 & 500 & 1 \\
\hline 3 & 540 & 1 & 600 & 1 \\
\hline 4 & 300 & 1 & 750 & 1 \\
\hline 5 & 550 & 0 & 300 & 0 \\
\hline 6 & 200 & 3 & 250 & 3 \\
\hline 7 & 300 & 1 & 480 & 1 \\
\hline 8 & 180 & 3 & 250 & 3 \\
\hline 9 & 300 & 1 & 380 & 1 \\
\hline 10 & 160 & 1 & 240 & 1 \\
\hline 11 & 330 & 3 & 200 & 3 \\
\hline 12 & 250 & 3 & 130 & 3 \\
\hline
\end{tabular}


UDS: The maximum cystometric capacity, compliance, and detrusor pressure at the maximum cystometric capacity before percutaneous RF sacral rhizotomy

The maximum cystometric capacity was $263.1 \pm 192.4$ $\mathrm{ml}$, compliance was $5 \pm 5.8 \mathrm{ml} / \mathrm{cmH} 2 \mathrm{O}$, and detrusor pressure at the maximum cystometric capacity was $44.9 \pm 32.7$ cmH2O.

\section{DISCUSSION}

The purpose of neurogenic bladder management in spinal cord injured patients is to maintain pressure of detrusor and minimize residual urine for normal urinary bladder function, and consequently preserving renal function and decreasing urinary tract complications. ${ }^{11}$ Most of the patients with neurogenic detrusor overactivity can be treated using an anticholinergic agent, with or without simultaneous CIC. However, these medications can cause dry mouth, constipation, nausea, and visual field defects. This is particularly the case of conservative refractory patients who are in need of alternative management. ${ }^{1}$ To reduce these side effects, Ekstrom et al. ${ }^{4}$ performed an intravesical instillation of atropine and phentolamine. Shin et al. ${ }^{20}$ demonstrated that an administration of intravesical oxybutynin improved maximal bladder capacity and compliance, as well as lowered maximal detrusor pressure. They added that this could be a safe and effective alternative management of neurogenic bladder in SCI. ${ }^{2,4}$ However, there were problems, including a discomfort in the vesicle, infection of urinary tract, and temporary effect of improving compliance. The treatment of Capsaicin and Resinferatoxin in the neurogenic bladder increases the maximal bladder volume and compliance, and decreases the maximal detrusor muscle pressure. However, treatment of capsaicin irritates the bladder wall, leading to pain. Hence, this method is not generally accepted in clinical practice. Resinferatoxin has a similar effect with the Capsaicin treatment and does not induce pain in patients, but it is difficult for patients to use the drugs and its effectiveness is very short in duration. ${ }^{12,13}$ The stretch therapy of bladder can increase the maximal bladder volume in a short time and attenuate the symptoms of urinary incontinence. However, it causes the bladder to disrupt and infect the urinary tract. There is also a lack of long-term clinical test findings. ${ }^{2,14-16}$

Schurch et al. has reported the management of direct injection of Botulinium toxin A in the detrusor muscle of the neurogenic bladder in SCI patients to alleviate the discomfort of irritation and urinary tract infection. They demonstrated that the injection significantly increased the maximal bladder volume and decreased the intravesicular pressure and frequency of urinary incontinence. However, they did not mention the long-term effects of treatment, after 6 months; thus, the duration of Botulinum toxin A's clinical effects remain uncertain. ${ }^{3}$

Surgical treatment is also considered for intolerable neurogenic bladder. It is effective in reducing urinary incontinence and increasing maximal bladder capacity by controlling detrusor hyperactivity. However, this surgical procedure destroys nerve fibers irreversibly, it affects the regeneration of spinal nerves, it weakens the urethral sphincter and pelvic floor muscles, and it suppresses reflex erection and reflex ejaculation in males. ${ }^{5,6}$

RF uses heat to ablate the nervous tissue and produces electrodes with an oscillating high frequency. RF disrupts the nervous tissues surrounding the electrode non-selectively. It can regulate the lesioning by thermoregulation. It makes coagulated lesion, which blocks the nerve conduction under $45^{\circ} \mathrm{C}$, and ablate nervous tissue irreversibly over $45^{\circ} \mathrm{C} .{ }^{17}$

In this study, RF was used to ablate the parasympathetic nervous system at the S2-S4 in the same manner with oscillating high frequency electrode. A lower urinary tract is controlled by the parasympathetic and somatic nervous system at S2-S4 and the sympathetic nervous system at T11-L2. It is based on controlling bladder function that cooperates with voiding reflexes by sacral reflex arcs and detrusor-sphincter synergia by brain stem cortical inhibition through the micturitional reflex center. Sensations of the bladder and urethra are transported to the central nervous system by the somatic and autonomic nervous systems. Bladder filling triggers stretch receptors distributed at the detrusor muscles and signals are transmitted to the sacral reflex centers by sympathetic nerves. ${ }^{18}$ Successful bladder denervation in the form of RF sacral rhizotomies of the S2-S4 segments for the treatment of neurogenic detrusor overactivity was first described by Mulcahy et al. ${ }^{8,9}$ Since Ferreira et al. ${ }^{19}$ was successful in increasing bladder capacity and decreasing intravesical pressure at the bilateral S3 level of RF sacral rhizotomy, we have attempted to interrupt the bilateral S2 or S3 roots. If there were difficulties approaching S2 or S3 roots 
due to bowel gas or anatomical problem, S4 root were targeted. Eleven patients diagnosed with UDS neurogenic detrusor overactivity had increased maximal bladder volume and intervals of urination and decreased urinary incontinence after RF. One patient who was diagnosed with UDS detrusor areflexia, but had vesicoureteral reflux, urinary frequency, and incontinence, also had improved clinical symptoms and maximal bladder capacity.

RF sacral rhizotomy is a procedure that is only minimally invasive, possible to perform repeatedly, reduces side effects of the urinary tract, is safe for regional infection, costs minimally, has a shortened hospital recovery period, and provides a faster return to daily activities. Furthermore, because this procedure takes longer for the injured nerve to recover than traumatic nerve damage, it will be helpful to keep up with these treatment effects for a period of time. In this study, 3 of the 12 patients were evaluated by the VCUG after 1 year of procedure. Consistent with our expectations, 2 patients had maintained their maximal bladder volume and 1 patient experienced an increase. The rest of the patients had missed longterm follow-ups due to low compliance or did not reach 1 year after procedure. To evaluate the long-term effects of therapy, more patients are needed beyond the one year of therapy period for the study to provide meaningful clinical result.

In this study, $17 \%$ of the enrolled patients have decreased maximal bladder volume in VCUG. However, clinical maximal bladder volume, average CIC volume, and intervals of urination increased and quantity of incontinence decreased in all treated patients. Moreover, none of the patients had pain, focal discomfort in the treated region, or sexual dysfunction. Based on these results, RF is safe, has few complications, and valid for neurogenic bladder by decreasing the incontinence and increasing the bladder volume. One limitation of our study was in not evaluating the long-term effects of detrusor pressure and compliance. Further studies are needed to identify the long-term effects of radiofrequency sacral rhizotomy to neurogenic detrusor overactivity.

\section{CONCLUSION}

This study confirms the potential efficacy of percutaneous RF sacral rhizotomy in reducing urinary incontinence and increasing the bladder volume to neurogenic detrusor overactivity. No areflexic bladder, sphincter dysfunction, or sexual complication occurred. Therefore, percutaneous RF sacral rhizotomy is a safe and valuable treatment option for neurogenic detrusor overactivity in SCI.

\section{REFERENCES}

1. Noronha-Blob L, Lowe VC, Peterson JS, Hanson RC. The anticholinergic activity of agents indicated for urinary incontinence is an important property for effective control do bladder dysfunction. J Pharmacol Exp Ther 1989; 251: 586-593

2. Buyse G, Waldeck K, Verpoorten C, Bjork H, Casaer P, Andersson KE. Intravesical oxybutynin for neurogenic bladder dysfunction: less systemic side effects due to reduced first pass metabolism. J Urol 1998; 160: 892896

3. Schurch B, de Seze M, Denys P, Chartier-Kastler E, Haab F, Everaert K, Plante P, Perrouin-Verbe B, Kumar C, Fraczek S, et al. Botulinum toxin type A is a safe and effective treatment for neurogenic urinary incontinence: results of a single treatment, randomized, placebo controlled 6-month study. J Urol 2005; 174: 196-200

4. Ekstrom B, Andersson KE, Mattiason A. Urodynamic effects of intravesical instillation of atropine and phentolamine in patients with detrusor hyperactivity. J Urol 1993; 149: 155-158

5. Brindley GS. The first 500 patients with sacral anterior root stimulator implants: general description. Paraplegia 1994; 32: 795-805

6. Popovic MR. Sacral root stimulation. Spinal Cord 2002; 40: 431

7. Kapural L, Mekhail N. Radiofrequency ablation for chronic pain control. Curr Pain Headache Rep 2001; 5: 517-525

8. Mulcahy JJ, Young AB. Percutaneous radiofrequency sacral rhizotomy in the treatment of the hyperreflexic bladder. J Urol 1978; 120: 557-558

9. Mulcahy JJ, Young AB. Long-term follow-up of percutaneous radiofrequency sacral rhizotomy. Urol 1990; 35: 76-77

10. Weibing S, Dongwen W. Relationship between the bladder trabeculation grades and pressure of detrusor in benign prostatic hyperplasia. China J Mod Med 
2010; 20: 723-725

11. Arnold EP, Fukui J, Anthony A, Utley WL. Bladder function following spinal cord injury: a urodynamic analysis of the outcome. Br J Urol 1984; 56: 172-177

12. Kim DY, Chancellor MB. Intravesical neuromodulatory drugs: capsaicin and resiniferatoxin to treat the overactive bladder. J Endourol 2000; 14: 97-103

13. de Seze M, Wiart L, de Seze MP, Soyeur L, Dosque JP, Blajezewski S, Moore N, Brochet B, Mazaux JM, Barat $\mathrm{M}$, et al. Intravesical capsaicin versus resiniferatoxin for the treatment of detrusor hyperreflexia in spinal cord injured patients: a double-blind, randomized, controlled study. J Urol 2004; 171: 251-255

14. Shin JC, Park CI, Kim YW, Park SY, Rha DW, Kim JE. Stretching therapy of neurogenic bladder in patients with spinal cord injury. J Korean Acad Rehabil Med 2003; 27 : 344-348

15. Helmstein K. Treatment of bladder carcinoma by a hydrostatic pressure technique. Br J Urol 1972; 44:

\section{4-450}

16. Dunn M, Ramsden PD, Roberts JB, Smith JC, Smith PJ. Interstitial cyctitis, treated by prolonged bladder distension. Br J Urol 1977; 49: 641-645

17. Sluijter M, Racz G. Technical aspects of radiofrequency. Pain Pract 2002; 2: 195-200

18. Blavias JG. Pathophysiology of lower urinary tract dysfunction. Urol Clin North Am 1985; 12: 215-224

19. Ferreira RS, Levi d'Ancona CA, Dantas-Filho VP, Rodrigues Netto N Jr, Miyaoka R. Percutaneous radiofrequency sacral rhizotomy in the treatment of neurogenic detrusor overactivity in spinal cord injured patients. Actas Urol Esp 2011; 35: 325-330

20. Shin JC, Park CI, Kim YR, Bang IK, Kim JE. Clinical effectiveness of intravesical oxybutynin instillation in spinal cord injured patients with hyperreflexic or hypertonic neurogenic bladder. J Korean Acad Rehabil Med 2000; 24: 28-34 